\title{
Excruciating pain and itching occurring at the administration site after intravenous injection of dexamethasone - a prospective clinical study
}

\author{
Dr.Utkarsha Lokesh, Dr. Anubhav Jannu, Dr. Dona Bhattacharya
}

\begin{abstract}
Dexamethasone is been used preoperatively before many minor surgical procedures.It is believed that single dose of dexamethasone as premedication does not cause any side effect. However during our study conducted on the aftereffect of intravenous administration of dexamethasone an unusual side effect of itching and burning sensationaround abdomen occurred.
\end{abstract}

Keywords: steroids, dexamethasone, itching

\section{Introduction}

Corticosteroids are important and commonly used medications because of their potent antiinflammatory and immunosuppressive properties, These have been a mainstay of treatment for many conditions, including rheumatological conditions (eg, rheumatoid arthritis temporal arteritis, polymyalgia rheumatica, systemic lupus erthematosus [SLE]), allergic reactionsm hepatitis obstructive lung diseases (eg, asthma, chronic obstructive pulmonary disease), and inflammatory bowel diseases ${ }^{1}$. Moreover glucocorticoids are being used pre-operatively before minor surgical procedures to decrease post operativeedema by inhibiting the release of pain mediators. However it is shown to cause certain post injection discomfort. Intravenous injection of dexamethasone causes transient decrease In blood potassium levels which results in post-injection itching and burning sensation ${ }^{1}$.

\section{Materials \& Methods}

For this study, 200 patients (including 100 males and 100 females)who required minor oral surgical treatment were selected. Written consent was obtained from these patients, Pre-operatively patient's serum sodium and potassium levels were evaluated and recorded. Before initiating the minor oral surgical procedure $2 \mathrm{ml}$ of $8 \mathrm{mg}$ Dexamethasone injection was given intravenously using 22 gauge needle attached to $5 \mathrm{ml}$ leurlok syringes. Post injection, the patient was enquired for the presence or absence of itching and pain in the region of injection. The time of onset of the pain and duration of the pain was noted in all the patients of either group. The time of onset was defined as a time when patient reported the pain or pruritis immediately after complete administration of dexamethasone. The intensity of pain was assessed with 11 point Numeric pain scale (NPS) (0-10 cm pain score) and Simple descriptive pain intensity scale (SDP) (no pain, mild pain, moderate pain and Severe pain). $\mathrm{P}$ value of $<0.05$ was considered as significant. A Chi-Square test was applied for defining statistically significant pain. Any other adverse effect like appearance of erythema, rashes or induration was noted. Following which patient's blood was withdrawn and sodium and potassium levels were evaluated. The readings obtained were tabulated and analysed.

\section{Results}

Table 1 shows that the two groups were similar with respect to age, weight and height. Seventy percentile male patients suffered no pain as compared to $43 \%$ female patients $(\mathrm{p}<0.05)$. Only $30 \%$ male patients had suffered pain as compared to $57 \%$ female patients. The incidence of itching at administration site was similar in both groups (36\% vs $48 \%$ ) although it was individually significant (Table 2). The mean time of onset of pain/ pruritis was 11 seconds in group 1 ad 6 seconds in group 2. The mean duration of persistence of pain/ itching was 19 seconds and 22 seconds in group 1 and 2 respectively.

\begin{tabular}{|l|l|l|l|l|}
\hline Pain & \multicolumn{2}{|l|}{ Group1 (n=100 males) } & \multicolumn{2}{l|}{ Group2(n=100 females) } \\
\hline & $\begin{array}{l}\text { No. of } \\
\text { patients }\end{array}$ & Percentage & $\begin{array}{l}\text { No. of } \\
\text { patients }\end{array}$ & Percentage \\
\hline No pain & 70 & $70 \%$ & 43 & $43 \%$ \\
\hline Pain & 30 & $30 \%$ & 57 & $57 \%$ \\
\hline Itching other & 36 & $36 \%$ & 48 & $48 \%$ \\
\hline $\begin{array}{l}\text { Any } \\
\text { side effect }\end{array}$ & 0 & 0 & 0 & 0 \\
\hline
\end{tabular}




\begin{tabular}{|l|l|l|}
\hline Parameters & Group 1 & Group 2 \\
\hline Mean age & $26 \pm 3.6$ & $23 \pm 2.6$ \\
\hline Mean weight & $58.6 \pm 4.3$ & $49.8 \pm 3.8$ \\
\hline Mean height & $168 \pm 3.1$ & $160 \pm 2.8$ \\
\hline
\end{tabular}

\begin{tabular}{|l|l|l|}
\hline Parameters & Group 1 & Group 2 \\
\hline Mean onset (sec) & $11 \pm 1.7$ & $6 \pm 0.6$ \\
\hline $\begin{array}{l}\text { Mean duration } \\
(\mathrm{sec})\end{array}$ & $19 \pm 1.3$ & $22 \pm 1.8$ \\
\hline
\end{tabular}

\section{Discussion}

Dexamethasone is a synthetic adrenocorticosteroid with glucocorticoid activity. It is one of the most active glucocorticoids, being about 25 to 30 times as potent as hydrocortisone. Unlike hydrocortisone, dexamethasone had little if any mineralocorticoid activity ${ }^{2}$. DBL ${ }^{\mathrm{TM}}$ Dexamethasone Sodium Phosphate injection is a clear colourless solution, free from visible particulate matter. Each millilitre of solution contains dexamethasone sodium phosphate equivalentto $4 \mathrm{mg}$ of dexamethasone phosphate. The $8 \mathrm{mg} / 2 \mathrm{ml}$ vial formulation contains sodium citrate, disodium edetate and sodium sulphite Anhydrous ${ }^{3}$. No preservatives are present. Dexamethasone phosphate (or sodium) is absorbed rapidly following intramuscular or intravenous injection. Intramuscular injections of dexamethasone phosphate give maximum plasma concentrations of dexamethasone at 1 hour. The biological half life of dexamethasone is about 190 minutes. $\mathrm{N}$ the circulation, small amounts of dexamethasone are bound to plasma protein. Synthetic corticosteroids such as dexamethasoneare less extensively protein bound and more slowly metabolised than hydrocortisone ${ }^{5}$. Dexamethasone penetrates into tissue fluids and cerebrospinal fluids. Metabolism occurs in most tissues, but primarily in the liver. The inactive metabolites are excreted in the urine, mainly as glucuronides and sulphates, but also as unconjugated metabolites ${ }^{6}$. Small amounts of unchanged drug are also excreted in the urine. Up to $65 \%$ of a dose of dexamethasone is excreted in the urine within 24 hours $^{10}$.

Perron et al. [3,11] performed a small prospective study in which 20 patients experienced pruritis in many patients after the administration of intravenous dexamethasone sodium phosphate ${ }^{4}$. The authors further tried to find the association between appearance of pruritis and female sex but concluded the study with recommendation that steroid should be diluted in $50 \mathrm{ml}$ saline and must be administered in 5-10 minutes. Their results are also similar to the present study where the incidence of perinealpruritis was more in group 2 (female patients) and it was statistically significant $(\mathrm{p}<0.05)$. The pharmacological mechanism explaining this phenomenon remains poorly understood, but could be related to the phosphate ester of the corticosteroid since perineal irritation has been described with hydrocortisone-21-phosphate sodium and prednisolone phosphate ${ }^{6}$. No detailed explanations is mentioned even on intensive medline search. It has been explained that the pathogenesis of perinealpruritis/ pain has been may be related to corticosteroid phosphate esterssuch as dexamethasone sodium phosphate (as used in our cases) to cause perineal pain and irritation Also itching at the site of administration is said to occurdue to transient mild hypokalemia which is usually observed after I.V administration. This is because $5 \%$ of potassium is present in blood vessels ${ }^{8}$. Both the incidence and severity may increase as the organic phosphate content of the injection increases. The lesser duration of pain might be due to hydrolysis of compound to phosphate ions and dexamethasone ${ }^{7}$. However, the pathophysiology of this rare side-effect still remains unknown and further research is required. Fortunately this adverse effect diminishes on its own as the compound is hydrolysed and it has not produced any postoperative prolonged effect.

\section{References}

[1]. Thomas VI (1986) More on dexamethasone induced perineal irritation. N Engl J med 314: 1643-1644.

[2]. Neff SP, Stapelberg E, Warmington A Excruciating perineal pain after intravenous dexamethasone. Anaesth Intensive Care 2002 30: 370-371.

[3]. Singh et al., Intravenous Dexamethasone Causes Perineal Pain and Pruritis, J Anesthe Clinic Res 2011.

[4]. Young, D.B., and T.E. Jackson.. Effects of aldosterone on potassium distribution. Am. J. Physiol. 243(Regulatory Integrative Comp. Physiol. 12) 1982:R526-R530.

[5]. El Mernissi, G., and A. Doucet. Short-term effects of aldosterone on renal sodium transport and tubular Na-K-ATPase in the rat. Pfltigers Arch 1983, 399:139-146.

[6]. Mujais, S.K., M.A. Chekal, W.J. Jones, J.P.HAYSLETT, and A.I.Katz.. Regulation of renal Na-K-ATPase I the rat. Role of the natural mineralo- and glucocorticoid hormones. J.Clin. Invest.1984 73:13-19.

[7]. E.Sarneset all. Incidence and US costs of Corticosteroid-Assosiated Adverse

[8]. Events: A systemic Literature Review; Clinical Therapeutics/Volume 33, Number 10,2011

[9]. Fardet L, FlahaultA, Kettanaeh A, et al. Corticosteroid -induced clinical adverse events: frequency, risk factors and patient's opinion. Br J Dermatol. 2007;157:142-148

[10]. Huscher D, Thiele K, Gromnica-Ihle E, et al. Dose-related atterns of glucocorticoid-induced side effects. Ann RheumDis.2009;68:1119-1124. 